\title{
Desempenho agronômico de feijão-caupi e milho semeados em faixas na safrinha
}

\author{
Aline de Oliveira Matoso(1), Rogério Peres Soratto(1), Gessi Ceccon ${ }^{(2)}$, \\ Priscila Gonzáles Figueiredo ${ }^{(1)}$ e Antonio Luiz Neto Neto(3)
}

\begin{abstract}
(1)Universidade Estadual Paulista, Faculdade de Ciências Agronômicas, Departamento de Produção e Melhoramento Vegetal, Campus de Botucatu, Caixa Postal 237, CEP 18603-970 Botucatu, SP. E-mail: matosoagronomia@gmail.com, soratto@fca.unesp.br, priscila_figueiredo3@hotmail.com (2)Embrapa Agropecuária Oeste, Caixa Postal 661, CEP 79804-970 Dourados, MS. E-mail: gessi.ceccon@embrapa.br ${ }^{(3)}$ Universidade Federal da Grande Dourados, Faculdade de Ciências Agrárias, Rodovia Dourados-Itahum, Km 12, CEP 79804-970 Dourados, MS. E-mail: aln_neto@hotmail.com
\end{abstract}

Resumo - O objetivo deste trabalho foi avaliar o desempenho agronômico de cultivares de feijão-caupi e de milho, em monocultivo e em cultivo consorciado em faixas, na safrinha. Foram realizados experimentos, em Dourados, MS (2009 e 2010), e em Botucatu, SP (2010). Utilizou-se o delineamento experimental de blocos ao acaso, com parcelas subdivididas e quatro repetições. As parcelas com feijão-caupi foram constituídas por três sistemas de cultivo (em faixas com variedade ou híbrido de milho, além do cultivo solteiro) e as subparcelas, por três cultivares de feijão-caupi (BRS Guariba, BRS Novaera e BRS Xiquexique). As parcelas com milho foram constituídas por duas cultivares de milho (variedade BR 473 e híbrido BRS 1030 ou BRS 1010), e as subparcelas, por quatro sistemas de cultivo (em faixas com as três cultivares de feijão-caupi e solteiro). O sistema de consórcio em faixas consistiu de quatro fileiras de feijão-caupi com quatro fileiras de milho. O consórcio proporcionou um uso mais eficiente da terra. As cultivares de feijão-caupi apresentaram desempenho produtivo semelhante entre si, quando cultivadas em faixas com o milho. O híbrido de milho é mais produtivo que a variedade, tanto no cultivo solteiro quanto no consorciado.

Termos para indexação: Vigna unguiculata, Zea mays, componentes de produção, cultivo intercalar, índice de equivalência de área, sistema de cultivo.

\section{Agronomic performance of cowpea and corn sown in strip-intercropping in the off-season}

\begin{abstract}
The objective of this work was to evaluate the agronomic performance of cowpea and corn cultivars in single cropping and in strip-intercropping in the off-season. The experiments were carried out in Dourados, MS (2009 and 2010), and Botucatu, SP (2010), Brazil. A randomized complete block design was used, in a split-plot arrangement with four replicates. The plots with cowpea consisted of three cropping systems (intercropped with corn variety or corn hybrid, and single cropped), and the subplots of three cowpea cultivars (BRS Guariba, BRS Novaera, and BRS Xiquexique). The plots with corn consisted of two corn cultivars (variety BR 473 and hybrid BRS 1030 or BRS 1010), and the subplots of four cropping systems (intercropped with the three cowpea cultivars and single cropped). The strip-intercropping system consisted of four rows of cowpea and four rows of corn. The intercropping led to a more efficient use of the land. Yield performance between cowpea cultivars did not differ when they were strip-intercropped with corn cultivars. The corn hybrid was more productive than the variety, both in single cropping and in intercropping.
\end{abstract}

Index terms: Vigna unguiculata, Zea mays, yield components, intercropping, area equivalency index, cropping system.

\section{Introdução}

O consórcio é uma das principais alternativas para a melhor utilização dos recursos naturais disponíveis (Rodrigo et al., 2001), pois permite o uso mais eficiente da terra, pelo melhor aproveitamento de energia solar, nutrientes, água e $\mathrm{CO}_{2}$, além de proporcionar maior estabilidade e renda ao produtor do que o monocultivo (Brintha \& Seran, 2009; Guedes et al., 2010; Souza et al., 2011).

O cultivo do milho (Zea mays L.) no período de safrinha tem ganhado importância nos últimos anos, em consequência das poucas alternativas econômicas viáveis para a safra de outono/inverno, e é instrumento 
fundamental para complementar o abastecimento no país (Shioga et al., 2004). Porém, essa modalidade de cultivo apresenta risco de perda de produtividade, em razão, principalmente, da ocorrência de deficiência hídrica. O cultivo do feijão-caupi [Vigna unguiculata (L.) Walp.] em consórcio com o milho, na safrinha, pode ser uma forma de minimizar os riscos de perda total da produção, caso ocorram veranicos durante o período de cultivo. Isso porque o feijão-caupi é tolerante a altas temperaturas e ao deficit hídrico, apresenta ciclo mais curto (média de noventa dias) e tem reduzida capacidade competitiva (Bertini et al., 2009). Entretanto, o cultivo consorciado pode limitar o uso de máquinas, o que aumenta os custos de produção (Portes, 1996). Dessa forma, o sistema de semeadura em faixas alternadas, ou consórcio intercalar, pode ser uma alternativa.

O cultivo em faixas alternadas consiste na semeadura de duas ou mais culturas numa mesma área; cada cultura com duas ou mais fileiras, formando faixas. Essas faixas podem ser suficientemente largas para permitir a mecanização, sem que se perca a vantagem da associação. Além de permitir o manejo independente de cada cultura, o que favorece a mecanização dos tratos culturais, esse sistema de cultivo também contribui para o melhor aproveitamento de luz solar (Tsubo et al., 2002; Awal et al., 2006), água (Souza et al., 2011) e nutrientes (Rowe et al., 2005; Dahmardeh et al., 2010) pelas culturas, com uso mais eficiente da área. O cultivo em faixas também contribui para a redução da erosão; possibilita a diversificação da produção, no espaço e no tempo; favorece o controle de plantas daninhas; e contribui para a fertilidade do solo, pela ciclagem de nutrientes e pela fixação de $\mathrm{N}_{2}$, quando associado com leguminosas (Sermenh et al., 2007).

No entanto, as cultivares de milho à disposição dos agricultores brasileiros foram criadas sem se considerar a exploração em consórcio. Segundo Costa et al. (2010), definir cultivares adaptadas aos sistemas de consórcio pode melhorar o desempenho do sistema e a produtividade das culturas consortes. Contudo, são praticamente inexistentes informações sobre $\mathrm{o}$ desempenho de cultivares de feijão-caupi cultivadas em faixas com o milho, especialmente no período da safrinha, nas regiões Centro-Oeste e Sudeste do Brasil, onde a cultura do milho tem grande importância e a cultura do feijão-caupi tem apresentado grande expansão.
O objetivo deste trabalho foi avaliar o desempenho agronômico de cultivares de feijão-caupi e de milho, em monocultivo e cultivo consorciado em faixas, na safrinha.

\section{Material e Métodos}

Foram conduzidos três experimentos, dois em Dourados, $\mathrm{MS}\left(22^{\circ} 18^{\prime} \mathrm{S}, 53^{\circ} 16^{\prime} \mathrm{W}\right.$, a $408 \mathrm{~m}$ de altitude), em 2009 e 2010 , e um em Botucatu, SP (22 51'S, $48^{\circ} 26^{\prime} \mathrm{W}$, a $740 \mathrm{~m}$ de altitude), em 2010.

Os solos das áreas experimentais foram classificados como Latossolo Vermelho distroférrico. Antes da instalação dos experimentos, foram realizadas amostragens de solo, na camada de 0-20 cm, para a determinação das características químicas e granulométricas (Tabela 1). As observações meteorológicas foram registradas durante a condução dos experimentos (Figura 1).

Utilizou-se o delineamento experimental de blocos ao acaso, com parcelas subdivididas e quatro repetições. As parcelas com feijão-caupi foram constituídas por três sistemas de cultivo - cultivo em faixas com a variedade (BR 437) ou com os híbridos de milho (BRS 1030 ou BRS1010), e cultivo solteiro - e as subparcelas consistiram das três cultivares avaliadas: BRS Guariba, BRS Novaera e BRS Xiquexique. Para

Tabela 1. Atributos químicos e granulométricos do solo, na camada de 0-0,20 m de profundidade, antes da instalação dos experimentos.

\begin{tabular}{lccc}
\hline Atributo $^{(1)}$ & \multicolumn{3}{c}{ Local $^{(2)}$} \\
\cline { 2 - 4 } & $\mathrm{MS} \mathrm{2009}$ & $\mathrm{MS} \mathrm{2010}$ & $\mathrm{SP} 2010$ \\
\hline $\mathrm{pH} \mathrm{CaCl}$ & & 5,7 & 5,2 \\
$\mathrm{MO}\left(\mathrm{g} \mathrm{dm}^{-3}\right)$ & 24 & 30 & 26 \\
$\mathrm{P}\left(\mathrm{mg} \mathrm{dm}^{-3}\right)$ & 15 & 18 & 21 \\
$\mathrm{H}+\mathrm{Al}\left(\mathrm{mmol}_{\mathrm{c}} \mathrm{dm}^{-3}\right)$ & 47 & 59 & 45 \\
$\mathrm{~K}\left(\mathrm{mmol}_{\mathrm{c}}{ }^{-3}\right)$ & 4,6 & 5,0 & 3,0 \\
$\mathrm{Ca}\left(\mathrm{mmol}_{\mathrm{c}} \mathrm{dm}^{-3}\right)$ & 52 & 40 & 54 \\
$\mathrm{Mg}\left(\mathrm{mmol}_{\mathrm{c}} \mathrm{dm}^{-3}\right)$ & 19 & 15 & 29 \\
$\mathrm{CTC}\left(\mathrm{mmol}_{\mathrm{c}} \mathrm{dm}^{-3}\right)$ & 123 & 118 & 131 \\
$\mathrm{~V}(\%)$ & 61 & 50 & 66 \\
Argila $\left(\mathrm{g} \mathrm{kg}^{-1}\right)$ & 713 & 713 & 513 \\
Silte $\left(\mathrm{g} \mathrm{kg}^{-1}\right)$ & 151 & 151 & 151 \\
Areia $\left(\mathrm{g} \mathrm{kg}^{-1}\right)$ & 136 & 136 & 336 \\
\hline
\end{tabular}

${ }^{(1)} \mathrm{Os}$ teores de $\mathrm{P}, \mathrm{K}, \mathrm{Ca}$ e $\mathrm{Mg}$ foram extraídos com Mehlich-1 nas amostras retiradas no Mato Grosso do Sul, e com resina de troca iônica, nas amostras retiradas em São Paulo. ${ }^{(2)} \mathrm{MS}$ 2009, experimento conduzido em Dourados, MS, em 2009; MS 2010, em Dourados, MS, em 2010; e SP 2010, em Botucatu, SP, em 2010. 

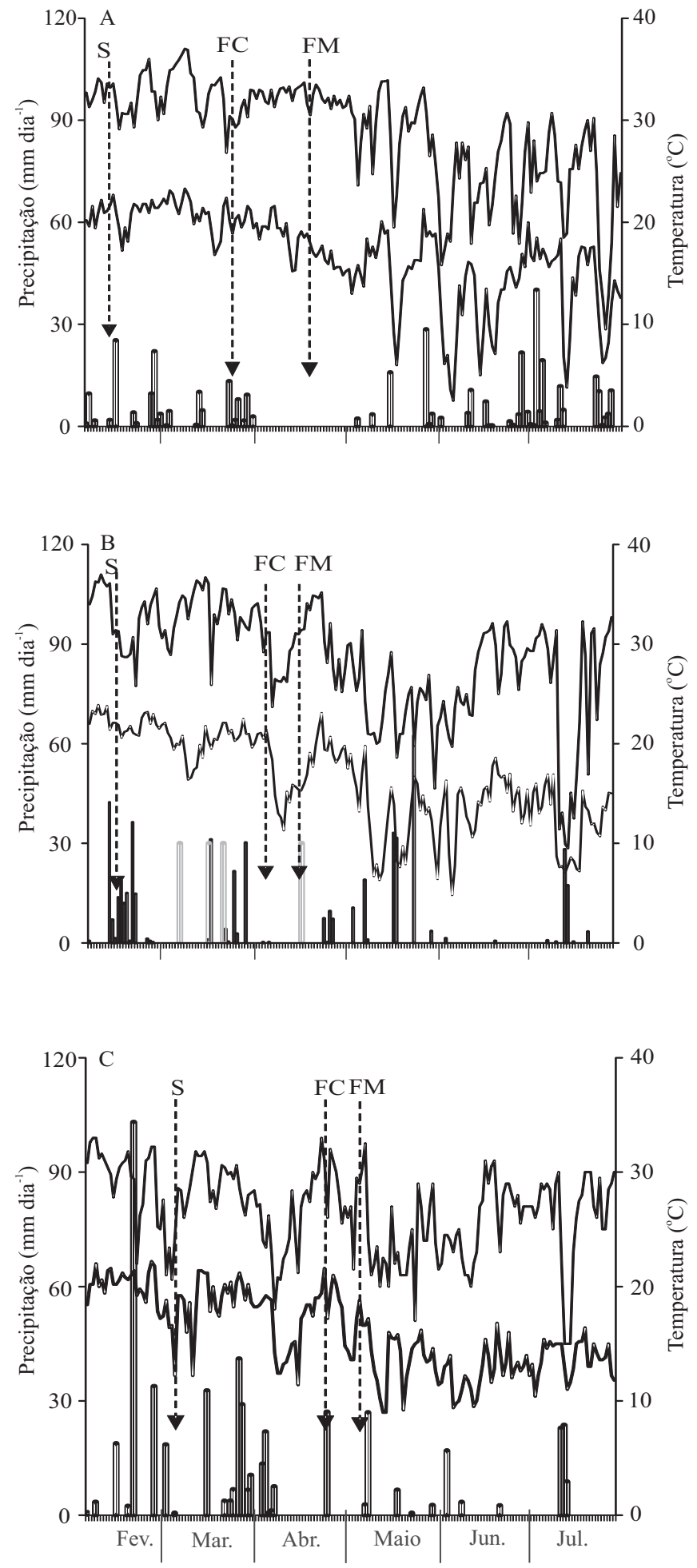

Figura 1. Precipitação pluvial (|), irrigação suplementar (|), e temperaturas máxima $(\rightarrow$ e mínima $\Theta$ registradas nas áreas experimentais durante o período de fevereiro a julho, em Dourados, MS, em 2009 (A) e 2010 (B), e em Botucatu, SP, em 2010 (C). S, data de semeadura; FC, data de florescimento do feijão-caupi; e FM, data de florescimento do milho. o milho, as parcelas consistiram de duas cultivares de milho (BR 473 e BRS 1030 ou BRS 1010), e as sub-parcelas de quatro sistemas de cultivo: em faixas com as cultivares de feijão-caupi BRS Guariba, BRS Novaera ou BRS Xiquexique, e cultivo solteiro. Em 2009, no experimento em Dourados, foi utilizado o híbrido de milho BRS 1030. Em 2010, foi utilizado o híbrido BRS 1010, tanto em Dourados quanto em Botucatu.

As cultivares de feijão-caupi foram originárias do Programa de Melhoramento Genético de Feijão-caupi da Embrapa Meio-Norte, e as cultivares de milho, do Programa de Melhoramento Genético da Embrapa Milho e Sorgo.

O sistema de consórcio consistiu da intercalação de faixas de quatro fileiras de feijão-caupi com faixas de quatro fileiras de milho. Ambas as culturas foram semeadas no espaçamento de $0,50 \mathrm{~m}$ entre fileiras. Foram semeadas oito sementes por metro de fileira, para a cultura do milho, e 13 sementes por metro de fileira para a do feijão-caupi. Aos 15 dias após a semeadura, foi realizado o desbaste, tendo-se deixado três plantas de milho por metro de fileira, o que equivaleria a $60 \mathrm{mil}$ plantas por hectare no cultivo solteiro e 30 mil plantas por hectare no cultivo em faixas. Para o feijão-caupi, foram deixadas sete plantas por metro de fileira, o que equivaleria a 140 mil plantas por hectare, no cultivo solteiro, e a 70 mil plantas por hectare, no cultivo em faixas.

No cultivo em faixas, cada unidade experimental consistiu de oito fileiras de $6 \mathrm{~m}$ de comprimento: quatro fileiras de milho (duas de cada lado da faixa de feijão-caupi) e quatro de feijão-caupi. No cultivo solteiro, cada unidade experimental foi constituída por quatro fileiras de $6 \mathrm{~m}$ de comprimento.

Em Dourados, a semeadura foi realizada mecanicamente, com semeadora de parcela, modelo SHP 249 (Semeato S/A Implementos Agrícolas, Passo Fundo, RS), em 11/2/2009 e 10/2/2010. A adubação de semeadura foi realizada com $200 \mathrm{~kg} \mathrm{ha}^{-1}$ do fertilizante formulado NPK (8-20-20), em ambos os anos. Em Botucatu, a abertura dos sulcos e a distribuição do fertilizante foram feitas com multisemeadora, modelo Personale Drill 13 (Semeato S/A Implementos Agrícolas, Passo Fundo, RS), e a semeadura foi realizada manualmente, em 3/3/2010. A adubação foi feita com $200 \mathrm{~kg} \mathrm{ha}^{-1}$ do fertilizante formulado NPK (8-28-16). 
$\mathrm{Na}$ cultura do feijão-caupi, foram avaliados: número de dias da emergência ao florescimento, ciclo, população final de plantas, número de vagens por planta, número de grãos por vagem, massa de 100 grãos e produtividade de grãos (em kg ha-1 , a 13\% de umidade em base úmida). Na cultura do milho, foram avaliados: número de dias da emergência ao florescimento, ciclo, população final de plantas, altura de plantas, número de espigas por plantas, número de grãos por espiga, massa de 100 grãos e produtividade de grãos (em kg ha-1, a $13 \%$ de umidade em base úmida). No experimento em Dourados, em 2009, o milho não foi colhido, em razão da estiagem prolongada (45 dias sem chuvas) e das altas temperaturas que ocorreram durante as fases de pendoamento, polinização e enchimento dos grãos da cultura (Figura 1), o que afetou o desenvolvimento das plantas de milho.

O índice de equivalência de área (IEA), utilizado para avaliar a eficiência do consórcio em relação aos monocultivos, foi obtido pela expressão: IEA $=(\mathrm{Ca} / \mathrm{Ma})+(\mathrm{Cb} / \mathrm{Mb})$, em que $\mathrm{Ca}$ e $\mathrm{Cb}$ são, respectivamente, as produtividades de grãos no consórcio das culturas do milho e do feijão-caupi; e Ma e $\mathrm{Mb}$ são, respectivamente, as produtividades de grãos no monocultivo das culturas do milho e do feijão-caupi (Willey, 1979). O consórcio foi considerado eficiente quando o IEA foi superior a 1 e ineficiente, quando foi inferior a esse valor (Vieira, 1985).

Os dados foram submetidos à análise de variância, e as médias, comparadas pelo teste Tukey, a 5\% de probabilidade.

\section{Resultados e Discussão}

O sistema de cultivo não alterou o número de dias para o florescimento, e as condições locais exerceram maior influência sobre essa característica, nas cultivares de feijão-caupi e milho (Tabela 2). Os ciclos das culturas foram menores nos experimentos realizados em Dourados, e maiores em Botucatu. As temperaturas mais elevadas e a menor precipitação pluvial em Dourados (Figura 1), especialmente no primeiro ano, contribuíram para esse resultado. Vale ressaltar que baixas temperaturas durante a noite podem prolongar o ciclo do feijão-caupi (Dumet et al., 2008). De acordo com Campos et al. (2010), a faixa de temperatura entre 20 e $30^{\circ} \mathrm{C}$ é considerada ótima para o feijão-caupi, enquanto temperaturas inferiores a $19^{\circ} \mathrm{C}$ aumentam o ciclo vegetativo e retardam o florescimento. A cultivar BRS Xiquexique demorou mais para atingir o florescimento pleno e apresentou ciclo mais longo que as demais, em todos os experimentos, o que está relacionado a características genéticas da cultivar.

Segundo Fancelli \& Dourado Neto (2003), o aumento da temperatura, principalmente a noturna, além de incrementar o processo respiratório, contribui para a aceleração no acúmulo de graus-dias, para o encurtamento do ciclo da cultura do milho, e para a redução do aparato fotossintético e, consequentemente, da quantidade de radiação interceptada e do potencial de produção.

Independentemente da cultivar utilizada, a maior população final do feijão-caupi foi observada no cultivo solteiro (Tabela 3). Como no cultivo em faixas a área ocupada pelo feijão-caupi foi metade da área utilizada no cultivo solteiro, essa menor população no consórcio era esperada.

O número de vagens por planta de feijão-caupi foi influenciado pela cultivar e pelo sistema de cultivo, no primeiro experimento em Dourados, e pela cultivar no segundo (Tabela 3). Em 2009, o cultivo solteiro proporcionou o maior número de vagens por plantas. Apesar de os sistemas de cultivo terem diferido entre si, em Dourados, em 2009, a redução do número de vagens por planta, no cultivo em faixas, não foi tão acentuada. Houve efeito apenas da cultivar utilizada sobre o número de grãos por vagem, nos três experimentos. De maneira geral, os maiores valores foram observados para 'BRS Xiquexique', seguida da 'BRS Guariba'. Essa variável apresenta alta herdabilidade genética, tendo sido pouco influenciada pelo ambiente.

A massa de 100 grãos de feijão-caupi não foi alterada pelos sistemas de cultivo, em nenhum dos experimentos; porém, diferiu entre as cultivares utilizadas (Tabela 3). A 'BRS Novaera', em todos os locais e os anos de estudo, apresentou a maior massa de 100 grãos, seguida da 'BRS Guariba'. Resultados semelhantes foram obtidos por Souza et al. (2004), em feijão-caupi consorciado com milho.

Quanto à produtividade de grãos, houve interação entre os fatores avaliados, em todos os experimentos (Tabela 4). No primeiro experimento, a cultivar BRS Novaera foi mais produtiva que as demais, no cultivo solteiro e em faixas com a variedade de milho. No entanto, quando cultivadas em faixas com 
o híbrido de milho, as cultivares de feijão-caupi tiveram produtividades de grãos estatisticamente iguais. Já no segundo experimento realizado em Dourados, a 'BRS Novaera' apresentou a menor produtividade no sistema solteiro e foi semelhante às demais nos sistemas de cultivo em faixas. No experimento em Botucatu, todas as cultivares de feijão-caupi se comportaram de maneira semelhante quanto à produtividade de grãos, independentemente do sistema de cultivo.

Apesar da relativa escassez de chuvas, especialmente durante a fase final de condução do primeiro experimento em Dourados, em 2009 (Figura 1), a produtividade de grãos do feijão-caupi não foi prejudicada (Tabela 4), pois, até a fase de florescimento da cultura, não houve estresse hídrico.

Tabela 2. Número médio de dias para o florescimento e duração do ciclo de cultivares de feijão-caupi e milho, em diferentes sistemas de cultivo, na safrinha ${ }^{(1)}$.

\begin{tabular}{|c|c|c|c|c|c|c|}
\hline \multirow[t]{2}{*}{ Tratamento } & \multicolumn{3}{|c|}{ № de dias para o florescimento } & \multicolumn{3}{|c|}{ Ciclo (dias) } \\
\hline & MS 2009 & MS 2010 & SP 2010 & MS 2009 & MS 2010 & SP 2010 \\
\hline & \multicolumn{6}{|c|}{ Feijão-caupi } \\
\hline \multicolumn{7}{|l|}{ Sistema de cultivo } \\
\hline Variedade $^{(2)}$ & 35 & 54 & 60 & 71 & 82 & 86 \\
\hline Híbrido $^{(3)}$ & 34 & 54 & 60 & 71 & 82 & 85 \\
\hline Solteiro & 35 & 55 & 58 & 71 & 82 & 86 \\
\hline \multicolumn{7}{|c|}{ Cultivar de feijão-caupi } \\
\hline BRS Guariba & 34 & 54 & 56 & 71 & 81 & 83 \\
\hline BRS Novaera & 33 & 54 & 56 & 70 & 80 & 83 \\
\hline \multirow[t]{2}{*}{ BRS Xiquexique } & 37 & 57 & 59 & 73 & 85 & 89 \\
\hline & \multicolumn{6}{|c|}{ Milho } \\
\hline \multicolumn{7}{|l|}{ Sistema de cultivo } \\
\hline BRS Guariba & 62 & 61 & 62 & - & 126 & 143 \\
\hline BRS Novaera & 62 & 61 & 61 & - & 123 & 143 \\
\hline BRS Xiquexique & 62 & 61 & 61 & - & 126 & 142 \\
\hline \multicolumn{7}{|l|}{ Cultivar de milho } \\
\hline Variedade & 64 & 62 & 63 & - & 131 & 145 \\
\hline Híbrido & 61 & 61 & 60 & - & 121 & 139 \\
\hline
\end{tabular}

(1)MS 2009, experimento conduzido em Dourados, MS, em 2009; MS 2010, em Dourados, MS, em 2010; e SP 2010, em Botucatu, SP, em 2010. ${ }^{\left({ }^{2}\right)}$ Variedade de milho BR 473. ${ }^{(3)}$ Híbrido simples de milho BRS 1030, em MS 2009, e BRS 1010 em MS 2010 e SP 2010.

Tabela 3. Componentes da produção de cultivares de feijão-caupi, em cultivo em faixas com cultivares de milho e solteiro, na safrinha ${ }^{(1)}$.

\begin{tabular}{|c|c|c|c|c|c|c|c|c|c|c|c|c|}
\hline \multirow[t]{2}{*}{ Tratamento } & \multicolumn{3}{|c|}{ População final (plantas por hectare) } & \multicolumn{3}{|c|}{ Vagens por planta } & \multicolumn{3}{|c|}{ Grãos por vagem } & \multicolumn{3}{|c|}{ Massa de 100 grãos (g) } \\
\hline & MS 2009 & MS 2010 & SP 2010 & MS 2009 & MS 2010 & SP 2010 & MS 2009 & MS 2010 & SP 2010 & MS 2009 & MS 2010 & SP 2010 \\
\hline \multicolumn{13}{|l|}{ Sistemas de cultivo } \\
\hline Variedade $^{(2)}$ & $57.033 b$ & $56.098 \mathrm{~b}$ & $57.308 \mathrm{~b}$ & $8,5 b$ & $7,5 \mathrm{a}$ & $8,2 \mathrm{a}$ & $13,6 \mathrm{a}$ & $12,4 \mathrm{a}$ & $12,6 \mathrm{a}$ & $15,7 \mathrm{a}$ & $15,7 \mathrm{a}$ & $15,7 \mathrm{a}$ \\
\hline Híbrido $^{(3)}$ & $58.724 b$ & $58.181 \mathrm{~b}$ & $53.276 \mathrm{~b}$ & $8,2 b$ & $7,5 \mathrm{a}$ & $8,7 \mathrm{a}$ & $13,4 \mathrm{a}$ & $13,0 \mathrm{a}$ & $12,6 \mathrm{a}$ & $15,7 \mathrm{a}$ & $15,7 \mathrm{a}$ & $15,8 \mathrm{a}$ \\
\hline Solteiro & $118.834 \mathrm{a}$ & $110.507 \mathrm{a}$ & $121.630 \mathrm{a}$ & $10,1 \mathrm{a}$ & $8,7 \mathrm{a}$ & $6,8 \mathrm{a}$ & $13,6 \mathrm{a}$ & $12,6 \mathrm{a}$ & $12,8 \mathrm{a}$ & $15,9 \mathrm{a}$ & $15,9 \mathrm{a}$ & $15,4 \mathrm{a}$ \\
\hline CV (\%) & 1,3 & 9,1 & 6,1 & 7,1 & 17,5 & 16,8 & 5,1 & 12,9 & 2,7 & 9,9 & 1,7 & 4,0 \\
\hline \multicolumn{13}{|l|}{ Cultivar } \\
\hline BRS Guariba & $79.116 \mathrm{a}$ & $74.179 \mathrm{a}$ & $76.767 \mathrm{a}$ & $8,0 \mathrm{~b}$ & $8,4 \mathrm{a}$ & $7,6 \mathrm{a}$ & $13,4 \mathrm{~b}$ & $13,0 \mathrm{a}$ & $12,9 b$ & $15,6 \mathrm{~b}$ & $15,6 \mathrm{~b}$ & $14,8 b$ \\
\hline BRS Novaera & $76.490 \mathrm{a}$ & $72.874 a$ & 76.361a & $9,3 \mathrm{a}$ & $6,7 b$ & $8,4 \mathrm{a}$ & $11,2 \mathrm{c}$ & $11,0 \mathrm{~b}$ & $10,1 \mathrm{c}$ & $17,6 \mathrm{a}$ & $17,6 \mathrm{a}$ & $19,4 \mathrm{a}$ \\
\hline BRS Xiquexique & $78.484 \mathrm{a}$ & $77.733 a$ & $79.085 \mathrm{a}$ & $9,4 \mathrm{a}$ & $8,8 \mathrm{a}$ & $7,9 \mathrm{a}$ & $15,8 \mathrm{a}$ & $14,0 \mathrm{a}$ & $15,0 \mathrm{a}$ & $14,1 \mathrm{c}$ & $14,1 \mathrm{a}$ & $12,5 \mathrm{c}$ \\
\hline CV (\%) & 2,5 & 5,8 & 3,8 & 10,2 & 16,0 & 15,1 & 4,0 & 8,5 & 6,6 & 14,1 & 5,0 & 3,6 \\
\hline
\end{tabular}

${ }^{(1)}$ Médias seguidas de letras iguais, nas colunas, não diferem pelo teste Tukey, a 5\% de probabilidade. MS 2009, experimento conduzido em Dourados, MS,

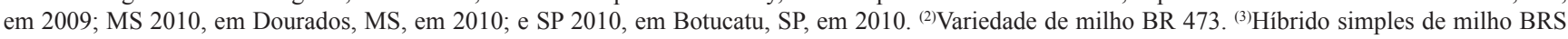
1030, em MS 2009, e BRS 1010 em MS 2010 e SP 2010. 
Contudo, a cultura do milho foi muito afetada pela deficiência hídrica na fase de florescimento, o que levou à perda total da produção do milho. Nessa situação, portanto, o cultivo do feijão-caupi em faixas alternadas evitou a perda total da produção da área, o que evidencia que esse sistema de cultivo pode ser uma alternativa interessante para proporcionar maior diversificação e estabilidade da produção de grãos na safrinha, sobretudo em épocas e regiões com risco de deficiência hídrica.

Em Dourados, em 2010, a produtividade da cultivar BRS Novaera, em cultivo solteiro, foi reduzida em mais de $55 \%$ em relação à safra anterior (Tabela 4), possivelmente em razão da sua maior suscetibilidade ao ataque de pulgões que transmitem o mosaico severo do feijão-caupi, que acarreta intenso nanismo e afeta, principalmente, o número de vagens por planta e de grãos por vagem (Tabela 3). A 'BRS Xiquexique', apesar de ter sido a menos produtiva no cultivo solteiro, no primeiro experimento, alcançou produtividades semelhantes

Tabela 4. Produtividade de grãos $\left(\mathrm{kg} \mathrm{ha}^{-1}\right)$ de cultivares de feijão-caupi, em cultivo em faixas com cultivares de milho e solteiro, na safrinha ${ }^{(1)}$.

\begin{tabular}{|c|c|c|c|}
\hline \multirow[t]{2}{*}{ Cultivar } & \multicolumn{3}{|c|}{ Sistema de cultivo } \\
\hline & Variedade $^{(2)}$ & Híbrido $^{(3)}$ & Solteiro \\
\hline & \multicolumn{3}{|c|}{ MS 2009} \\
\hline BRS Guariba & $632 \mathrm{bB}$ & $652 \mathrm{aB}$ & $1.465 \mathrm{bA}$ \\
\hline BRS Novaera & $744 \mathrm{aB}$ & $635 \mathrm{aB}$ & $1.756 \mathrm{aA}$ \\
\hline BRS Xiquexique & $675 \mathrm{abB}$ & $651 \mathrm{aB}$ & $965 \mathrm{cA}$ \\
\hline $\mathrm{CV}_{\text {parcela }}(\%)$ & \multicolumn{3}{|c|}{7,9} \\
\hline $\mathrm{CV}_{\text {subparcela }}(\%)$ & \multicolumn{3}{|c|}{6,7} \\
\hline & \multicolumn{3}{|c|}{ MS 2010} \\
\hline BRS Guariba & $563 \mathrm{aB}$ & $570 \mathrm{aB}$ & $1.231 \mathrm{aA}$ \\
\hline BRS Novaera & $434 \mathrm{aB}$ & $390 \mathrm{aB}$ & $779 \mathrm{bA}$ \\
\hline BRS Xiquexique & $674 \mathrm{aB}$ & $651 \mathrm{aB}$ & $1.454 \mathrm{aA}$ \\
\hline $\mathrm{CV}_{\text {parcela }}(\%)$ & \multicolumn{3}{|c|}{14,8} \\
\hline $\mathrm{CV}_{\text {subparcela }}(\%)$ & \multicolumn{3}{|c|}{21,9} \\
\hline & \multicolumn{3}{|c|}{ SP 2010} \\
\hline BRS Guariba & $674 \mathrm{aB}$ & $591 \mathrm{aB}$ & $1.180 \mathrm{aA}$ \\
\hline BRS Novaera & $637 \mathrm{aB}$ & $565 \mathrm{aB}$ & $1.164 \mathrm{aA}$ \\
\hline BRS Xiquexique & $715 \mathrm{aB}$ & $789 \mathrm{aAB}$ & $1.150 \mathrm{aA}$ \\
\hline $\mathrm{CV}_{\text {parcela }}(\%)$ & \multicolumn{3}{|c|}{25,4} \\
\hline $\mathrm{CV}_{\text {subparcela }}(\%)$ & \multicolumn{3}{|c|}{10,4} \\
\hline
\end{tabular}

${ }^{(1)}$ Médias seguidas de letras iguais, minúsculas nas colunas e maiúsculas nas linhas, não diferem pelo teste de Tukey, a $5 \%$ de probabilidade. MS 2009, experimento conduzido em Dourados, MS, em 2009; MS 2010, em Dourados, MS, em 2010; e SP 2010, em Botucatu, SP, em 2010. ${ }^{(2)}$ Variedade de milho BR 473. ${ }^{(3)}$ Híbrido simples de milho BRS 1030, em MS 2009, e BRS 1010 em MS 2010 e SP 2010. às demais cultivares quando cultivada em faixas (Tabela 4). Esse resultado é discordante do obtido por Santos (2007), que relatou que a produtividade de cultivares de feijão em cultivo solteiro é o principal fator que determina o seu desempenho no consórcio.

A cultivar de milho utilizada no consórcio não afetou a produtividade das cultivares de feijão-caupi (Tabela 4). Assim, semelhantemente ao constatado por Santos (2007) e Costa et al. (2010), não houve influência do maior ou do menor porte das plantas de milho sobre a produtividade do feijão-caupi.

Quanto à população final de plantas de milho, houve efeito da interação entre sistema de cultivo e cultivar, nos dois locais (Tabela 5). No cultivo solteiro, o híbrido BRS 1010 apresentou maiores populações de plantas que a variedade de milho, no experimento em Dourados, em 2010; porém, em Botucatu, em 2010, o

Tabela 5. Componentes da produção de cultivares de milho, em cultivo em faixas com cultivares de feijão-caupi e solteiro, na safrinha ${ }^{(1)}$.

\begin{tabular}{|c|c|c|}
\hline \multirow[t]{2}{*}{ Sistema de cultivo } & \multicolumn{2}{|c|}{ Cultivar de milho } \\
\hline & Variedade $^{(2)}$ & Híbrido $^{(3)}$ \\
\hline & \multicolumn{2}{|c|}{ População final de plantas (plantas por hectare) - MS 2010} \\
\hline BRS Guariba & $27.777 \mathrm{bB}$ & $31.111 \mathrm{bA}$ \\
\hline BRS Novaera & $29.259 \mathrm{bB}$ & $31.875 \mathrm{bA}$ \\
\hline BRS Xiquexique & $29.272 \mathrm{bA}$ & $30.208 \mathrm{bA}$ \\
\hline Solteiro & $47.500 \mathrm{aB}$ & $57.291 \mathrm{aA}$ \\
\hline $\mathrm{CV}_{\text {parcela }}(\%)$ & & \\
\hline \multirow[t]{2}{*}{$\mathrm{CV}_{\text {subparcela }}(\%)$} & & \\
\hline & \multicolumn{2}{|c|}{ População final de plantas (plantas por hectare) - SP 2010} \\
\hline BRS Guariba & $26.978 \mathrm{bA}$ & $30.000 \mathrm{bA}$ \\
\hline BRS Novaera & $29.773 \mathrm{bA}$ & $31.137 \mathrm{bA}$ \\
\hline BRS Xiquexique & $30.606 \mathrm{bA}$ & $31.667 \mathrm{bA}$ \\
\hline Solteiro & $63.636 \mathrm{aA}$ & $57.273 \mathrm{aB}$ \\
\hline$\overline{\mathrm{CV}_{\text {parcela }}(\%)}$ & & \\
\hline \multirow[t]{2}{*}{$\mathrm{CV}_{\text {subparcela }}(\%)$} & & \\
\hline & \multicolumn{2}{|c|}{ Número de grãos por espiga - MS 2010} \\
\hline BRS Guariba & $422,5 \mathrm{aA}$ & $406,3 \mathrm{aA}$ \\
\hline BRS Novaera & $420,8 \mathrm{aA}$ & $420,8 \mathrm{aA}$ \\
\hline BRS Xiquexique & $439,8 \mathrm{aA}$ & $398,3 \mathrm{aA}$ \\
\hline $\mathrm{CV}_{\text {parcela }}(\%)$ & & \\
\hline \multirow[t]{2}{*}{$\mathrm{CV}_{\text {subparcela }}(\%)$} & & \\
\hline & \multicolumn{2}{|c|}{ Número de grãos por espiga - SP 2010} \\
\hline BRS Guariba & $486,2 \mathrm{aA}$ & $435,2 \mathrm{aB}$ \\
\hline BRS Novaera & $429,8 \mathrm{bA}$ & $441,1 \mathrm{aA}$ \\
\hline BRS Xiquexique & $468,5 \mathrm{aA}$ & $445,4 \mathrm{aA}$ \\
\hline Solteiro & $469,8 \mathrm{aA}$ & $457,5 \mathrm{aA}$ \\
\hline$\overline{\mathrm{CV}_{\text {parcela }}(\%)}$ & \multicolumn{2}{|c|}{3,3} \\
\hline $\mathrm{CV}_{\text {subparcela }}(\%)$ & \multicolumn{2}{|c|}{4,3} \\
\hline $\begin{array}{l}\text { (1) Médias seguidas } \\
\text { não diferem pelo t } \\
\text { conduzido em Dour } \\
2010 \text {, em Botucatu, } \\
\text { milho BRS } 1030 \text {, el }\end{array}$ & $\begin{array}{l}\text { letras iguais, minúscul } \\
\text { e de Tukey, a } 5 \% \text { de } \\
\text { os, MS, em } 2009 \text {; MS } \\
\text {, em } 2010 .{ }^{(2)} \text { Variedade } \\
\text { MS } 2009 \text {, e BRS } 1010\end{array}$ & $\begin{array}{l}\text { aiúsculas nas linha } \\
\text { 2009, experiment } \\
\text { MS, em 2010; e S } \\
\text { Híbrido simples c } \\
010 \text {. }\end{array}$ \\
\hline
\end{tabular}

Pesq. agropec. bras., Brasília, v.48, n.7, p.722-730, jul. 2013 DOI: 10.1590/S0100-204X2013000700004 
resultado foi inverso. Em ambos os locais, as maiores populações de plantas foram observadas no sistema de cultivo solteiro, o que era esperado já que o dobro de sementes foi semeado nesse sistema, quando comparado aos sistemas de consórcio.

De modo geral, o híbrido de milho apresentou menor altura média de plantas, independentemente do sistema de cultivo (Tabela 6). O maior crescimento das cultivares de milho ocorreu em Botucatu, em 2010; entretanto, não foram constatadas diferenças entre os tratamentos. A ausência de diferenças nessa variável, em todos os sistemas de cultivo, pode ser explicada pela reduzida competição que as plantas de feijão-caupi exercem sobre as de milho. Segundo Flesch (2002), as diferenças em porte e arquitetura dessas duas espécies consorciadas favorecem $\mathrm{o}$ milho na competição por radiação solar; além disso, o milho, por ter um sistema radicular mais vigoroso, é favorecido em relação ao feijoeiro, na absorção de água e nutrientes.

O menor porte de plantas de milho em Dourados, no experimento de 2009, está relacionado à estiagem prolongada (45 dias sem chuvas) e às altas temperaturas que ocorreram durante as fases de pendoamento, polinização e enchimento dos grãos da cultura (Figura 1; Tabela 6), o que afetou o desenvolvimento das plantas de milho.

$\mathrm{O}$ número médio de espigas por planta não foi afetado pelo sistema de cultivo ou pela cultivar utilizada (Tabela 6). O número de espigas por planta é uma variável que reflete a competição pelos fatores de produção disponíveis no ambiente. As cultivares avaliadas apresentaram o mesmo comportamento tanto no cultivo consorciado, como no solteiro, o que pode ser atribuído à boa adaptação destes materiais aos sistemas de cultivo utilizados.

O número de grãos por espigas não foi afetado pelos fatores avaliados no experimento em Dourados, em 2010 (Tabela 5). Entretanto, em Botucatu, em 2010, houve interação entre os fatores. No cultivo consorciado com a cultivar de feijão-caupi BRS Guariba, o híbrido de milho (BRS 1010) apresentou menor número de grãos por espiga do que a variedade (BR 473). Contudo, a variedade de milho consorciada com a cultivar BRS Novaera apresentou menor número de grãos que nos demais sistemas. Portanto, não houve efeito significativo do sistema de cultivo sobre o híbrido de milho.

Quanto à massa média de 100 grãos, no milho, constatou-se apenas efeito da cultivar utilizada, em ambos os locais (Tabela 6). O híbrido apresentou massa de 100 grãos superior à da variedade. De acordo com Cruz et al. (2008), a massa de 100 grãos é uma característica influenciada pelo genótipo, pela disponibilidade de nutrientes e pelas condições climáticas durante os estádios de enchimento dos grãos.

Houve efeito significativo do sistema de cultivo e da cultivar de milho utilizada na produtividade de grãos do milho (Tabela 6); porém, não houve interação entre esses fatores, tanto em Dourados quanto em Botucatu. Em ambos os locais, a maior produtividade

Tabela 6. Altura de plantas, número de espigas por planta, massa média de 100 grãos e produtividade de grãos de cultivares de milho, em cultivo em faixas com cultivares de feijão-caupi e solteiro, na safrinha ${ }^{(1)}$.

\begin{tabular}{|c|c|c|c|c|c|c|c|c|c|}
\hline \multirow[t]{2}{*}{ Tratamento } & \multicolumn{3}{|c|}{ Altura de plantas $(\mathrm{cm})$} & \multicolumn{2}{|c|}{ Espigas por planta } & \multicolumn{2}{|c|}{ Massa de 100 grãos (g) } & \multicolumn{2}{|c|}{ Produtividade de grãos $\left(\mathrm{kg} \mathrm{ha}^{-1}\right)$} \\
\hline & MS 2009 & MS 2010 & SP 2010 & MS 2010 & SP 2010 & MS 2010 & SP 2010 & MS 2010 & SP 2010 \\
\hline \multicolumn{10}{|l|}{ Sistemas de cultivo } \\
\hline BRS Guariba & $1,3 \mathrm{a}$ & $1,6 \mathrm{a}$ & $1,7 \mathrm{a}$ & $1,1 \mathrm{a}$ & $1,0 \mathrm{a}$ & $28,0 \mathrm{a}$ & $26,8 \mathrm{a}$ & $2.890 \mathrm{~b}$ & $2.884 b$ \\
\hline BRS Novaera & $1,5 \mathrm{a}$ & $1,6 \mathrm{a}$ & $1,6 \mathrm{a}$ & $1,1 \mathrm{a}$ & $1,1 \mathrm{a}$ & $28,3 \mathrm{a}$ & $26,3 \mathrm{a}$ & $3.152 b$ & $3.019 \mathrm{~b}$ \\
\hline BRS Xiquexique & $1,4 \mathrm{a}$ & $1,6 \mathrm{a}$ & $1,7 \mathrm{a}$ & $1,1 \mathrm{a}$ & $1,0 \mathrm{a}$ & $28,0 \mathrm{a}$ & $27,6 \mathrm{a}$ & $2.840 \mathrm{~b}$ & $3.141 b$ \\
\hline Solteiro & $1,4 \mathrm{a}$ & $1,6 \mathrm{a}$ & $1,8 \mathrm{a}$ & $1,2 \mathrm{a}$ & $1,0 \mathrm{a}$ & $27,8 \mathrm{a}$ & $27,1 \mathrm{a}$ & $4.602 \mathrm{a}$ & $5.985 \mathrm{a}$ \\
\hline CV (\%) & 5,1 & 2,9 & 6,9 & 16,0 & 19,2 & 3,7 & 5,8 & 15,8 & 11,1 \\
\hline \multicolumn{10}{|l|}{ Cultivar de milho } \\
\hline Variedade $^{(2)}$ & $1,4 \mathrm{a}$ & $1,7 \mathrm{a}$ & $1,8 \mathrm{a}$ & $1,3 \mathrm{a}$ & $1,1 \mathrm{a}$ & $25,7 b$ & $23,2 b$ & $2.743 b$ & $2.964 b$ \\
\hline Híbrido $^{(3)}$ & $1,3 b$ & $1,5 b$ & $1,6 \mathrm{a}$ & $1,0 \mathrm{a}$ & $1,0 \mathrm{a}$ & $30,6 \mathrm{a}$ & $30,7 \mathrm{a}$ & $3.999 \mathrm{a}$ & $4.550 \mathrm{a}$ \\
\hline CV (\%) & 5,3 & 6,6 & 9,0 & 16,7 & 17,7 & 6,1 & 6,7 & 9,4 & 11,2 \\
\hline
\end{tabular}

${ }^{(1)}$ Médias seguidas de letras iguais, nas colunas, não diferem pelo teste Tukey, a $5 \%$ de probabilidade. MS 2009 , experimento conduzido em Dourados, MS, em 2009; MS 2010, em Dourados, MS, em 2010; e SP 2010, em Botucatu, SP, em 2010. ${ }^{(2)}$ Variedade de milho BR 473. ${ }^{(3)}$ Híbrido simples de milho BRS 1030, em MS 2009, e BRS 1010 em MS 2010 e SP 2010. 
foi obtida no sistema de cultivo solteiro, que diferiu de todos os sistemas consorciados. Além disso, a produtividade de grãos do milho foi semelhante em todos os sistemas consorciados, independentemente da cultivar de feijão-caupi utilizada. Santos (2007) também não observou efeito significativo de diferentes cultivares de feijão sobre a produtividade de grãos do milho. Cabe destacar que, no experimento em Dourados, em 2009, o milho não produziu grãos, em razão da ausência de chuvas durante as fases de pré-pendoamento e florescimento (Figura 1).

O híbrido de milho BRS 1010 foi mais produtivo que a variedade BR 473, independentemente dos sistemas de cultivo, em ambos os experimentos (Tabela 6), o que foi atribuído à sua boa adaptaptabilidade, à base genética (híbrido simples), à disposição das folhas (eretas) e ao menor porte das plantas.

O consórcio foi eficiente em todas as combinações de cultivares de milho e de feijão-caupi utilizadas, com exceção dos consórcios entre o híbrido de milho BRS 1010 e as cultivares de feijão-caupi BRS Guariba e BRS Novaera, em Botucatu (Tabela 7). Em Dourados, os sistemas mais eficientes em termos de uso da terra foram obtidos com os consórcios do híbrido de milho BRS 1010 e da variedade BR 473 e a cultivar de feijão-caupi BRS Novaera. Em Botucatu, o consórcio do híbrido BRS 1010 com a cultivar de feijão-caupi BRS Xiquexique apresentou IEA de 1,22. Esse resultado indica que, para que os monocultivos produzam a mesma quantidade de grãos que um hectare do consórcio, seriam necessários 0,69 ha de feijão-caupi e 0,53 ha de milho, o que totaliza 1,22 ha. Portanto, neste caso os monocultivos exigiram $22 \%$ a mais de área do que o cultivo em consórcio.

Tabela 7. Índice de equivalência de área do cultivo em faixas de cultivares de feijão-caupi e de milho, na safrinha, em Dourados, MS, e Botucatu, SP, em 2010 (MS 2010 e SP 2010, respectivamente).

\begin{tabular}{lcc}
\hline Tratamentos em consórcio & MS 2010 & SP 2010 \\
\hline Milho BR 473 + feijão-caupi BRS Guariba & 1,07 & 1,05 \\
Milho BR 473 + feijão-caupi BRS Novaera & 1,21 & 1,04 \\
Milho BR 473 + feijão-caupi BRS Xiquexique & 1,09 & 1,13 \\
Milho BRS 1010 + feijão-caupi BRS Guariba & 1,10 & 0,98 \\
Milho BRS 1010 + feijão-caupi BRS Novaera & 1,21 & 1,00 \\
Milho BRS 1010 + feijão-caupi BRS Xiquexique & 1,06 & 1,22 \\
\hline
\end{tabular}

BR 473, variedade; BRS 1010, híbrido.

\section{Conclusões}

1. As cultivares de feijão-caupi utilizadas apresentam desempenho semelhante entre si, no cultivo consorciado em faixas com cultivares de milho.

2. As menores produtividades de grãos das cultivares de feijão-caupi em consórcio estão mais relacionadas à menor população de plantas, empregada neste sistema de cultivo, do que à competição com as plantas de milho.

3. O híbrido de milho é mais produtivo que a variedade, tanto no monocultivo quanto em consórcio.

4. O cultivo consorciado em faixas de milho e feijão-caupi proporciona uso mais eficiente da terra do que o monocultivo dessas culturas.

\section{Agradecimentos}

À Fundação de Amparo à Pesquisa do Estado de São Paulo (Fapesp, proc. 2009/03724-4), pela concessão de bolsa à primeira autora; e ao Conselho Nacional de Desenvolvimento Científico e Tecnológico (CNPq), pela concessão de bolsa de Produtividade em Pesquisa ao segundo autor.

\section{Referências}

AWAL, M.A.; KOSHI, H.; IKEDA, T. Radiation interception and use by maize/peanut intercrop canopy. Agricultural and Forest Meteorology, v.139, p.74-83, 2006. DOI: 10.1016/j. agrformet.2006.06.001.

BERTINI, C.H.C. de M.; TEÓFILO, E.M.; DIAS, F.T.C. Divergência genética entre acessos de feijão-caupi do banco de germoplasma da UFC. Revista Ciência Agronômica, v.40, p.99-105, 2009.

BRINTHA, I.; SERAN, T.H. Effect of paired row planting of radish (Raphanus sativus L.) intercropped with vegetable amaranthus (Amaranthus tricolor L.) on yield components of radish in sandy regosol. Journal of Agricultural Sciences, v.4, p.19-28, 2009.

CAMPOS, J.H.B. da C.; SILVA, M.T.; SILVA, V. de P.R. da. Impacto do aquecimento global no cultivo do feijão-caupi, no Estado da Paraíba. Revista Brasileira de Engenharia Agrícola e Ambiental, v.14, p.396-404, 2010. DOI: 10.1590/S1415-43662010000400008.

COSTA, D.S. da; BARBOSA, R.M; SÁ, M.E. de. Sistemas de produção e cultivares de feijoeiro em consórcio com milho. Scientia Agraria, v.11, p.425-430, 2010.

CRUZ, C.S.S.; PEREIRA, F.R. da S.; SANTOS, J.R.; ALBUQUERQUE, A.W. de; PEREIRA, R.G. Adubação nitrogenada para o milho cultivado em sistema plantio direto, no Estado de Alagoas. Revista Brasileira de Engenharia Agrícola e Ambiental, v.12, p.62-68, 2008. DOI: 10.1590/ S1415-43662008000100009. 
DAHMARDEH, M.; GHANBARI, A.; SYAHSAR, B.A.; RAMRODI, M. The role of intercropping maize (Zea mays L.) and cowpea (Vigna unguiculata L.) on yield and soil chemical properties. African Journal of Agricultural Research, v.5, p.631-636, 2010.

DUMET, D.; ADELEKE, R.; FALOYE, B. Regeneration guidelines: cowpea. In: DULLOO, M.E.; THORMANN, I.; JORGE, M.A.; HANSON, J. (Ed.). Crop specific regeneration guidelines. Rome: CGIAR's System-Wide Genetic Resource Programme, 2008. p.1-8.

FANCELLI, A.L.; DOURADO NETO, D. Milho: estratégias de manejo para alta produtividade. Piracicaba: Esalq, 2003. 208p.

FLESCH, R.D. Efeitos temporais e espaciais no consórcio intercalar de milho e feijão. Pesquisa Agropecuária Brasileira, v.37, p.51-56, 2002. DOI: 10.1590/S0100-204X2002000100007.

GUEDES, R.E.; RUMJANEK, N.G.; XAVIER, G.R.; GUERRA, J.G.M.; RIBEIRO, R. de L.D. Consórcios de caupi e milho em cultivo orgânico para produção de grãos e espigas verdes. Horticultura Brasileira, v.28, p.174-177, 2010. DOI: 10.1590/ S0102-05362010000200006.

PORTES, T. de A. Produção de feijão nos sistemas consorciados. Goiânia: Embrapa-CNPAF, 1996. 50p. (Embrapa-CNPAF. Documentos, 71).

RODRIGO, V.H.L.; STIRLING, C.M.; TEKLEHAIMANOT, Z.; NUGAWELA, A. Intercropping with banana to improve fractional interception and radiation-use efficiency of immature rubber plantations. Field Crops Research, v.69, p.237-249, 2001. DOI: 10.1016/S0378-4290(00)00147-7.

ROWE, E.C.; NOORDWIJK, M.V.; SUPRAYOGO, D.; $\mathrm{CADISCH}, \mathrm{G}$. Nitrogen use efficiency of monoculture and hedgerow intercropping in the humid tropics. Plant and Soil, v.268, p.61-74, 2005. DOI: 10.1007/s11104-004-0227-2.

SANTOS, N.C.B. dos. Comportamento de cultivares de feijoeiro e de milho verde em cultivo solteiro e consorciado. 2007. 99p. Tese (Doutorado) - Universidade Estadual Paulista, Ilha Solteira.

SERMENH, T.; EVRENDILEK, F.; MAVI, K. Effects of strip intercropping and organic farming systems on quantity and quality of maize yield in a Mediterranean region of Turkey. Journal of Sustainable Agriculture, v.30, p.109-118, 2007. DOI: 10.1300/ J064v30n04_08.

SHIOGA, P.S.; OLIVEIRA, E.L. de; GERAGE, A.C. Densidade de plantas e adubação nitrogenada em milho cultivado na safrinha. Revista Brasileira de Milho e Sorgo, v.3, p.381-390, 2004.

SOUZA, L.S.B. de; MOURA, M.S.B. de; SEDIYAMA, G.C.; SILVA, T.G.F. da. Eficiência do uso da água das culturas do milho e do feijão-caupi sob sistemas de plantio exclusivo e consorciado no semiárido brasileiro. Bragantia, v.70, p.715-721, 2011. DOI: 10.1590/S0006-87052011000300030

SOUZA, M.L. de O.; TÁVORA, F.J.A.F.; BLEICHER, E.; PITOMBEIRA, J.B. Efeito do consórcio do milho (Zea mays L.) com feijão-de-corda (Vigna unguiculata (L.) Walp) no rendimento de grãos, uso eficiente da terra e ocorrência de pragas. Revista Ciência Agronômica, v.35, p.196-205, 2004.

TSUBO, M.; WALKER, S. A model of radiation interception and use by a maize-bean intercrop. Agricultural and Forest Meteorology, v.110, p.203-215, 2002. DOI: 10.1016/S0168-1923(01)00287-8.

VIEIRA, C. O feijão em cultivos consorciados. Viçosa: Ed. UFV, 1985. 134p.

WILLEY, R.W. Intercropping: its importance and research needs. Part. 1. Competition and yield advantages. Field Crop Abstracts, v.32, p.1-10, 1979. 